\title{
Bibliometric Analysis of the Research on Innovation Mechanism of Colleges in Civil-Military Inosculation
}

\author{
Hongfei Guo \\ Institute of Physical Internet, Jinan University \\ Zhuhai, 519070, China \\ E-mail: ghf-2005@163.com
}

Ru Zhang

Finance Department of International Business School, Jinan University Zhuhai, 519070, China

E-mail: zhangru@stu2016.jnu.edu.cn

Jincheng Shi (Corresponding author)

Department of science and technology, Jinan University

Guangzhou, 510632, China

E-mail: tshijc@jnu.edu.cn

\author{
Min Zou \\ School of Translation Studies, Jinan University \\ Zhuhai, 519070, China \\ E-mail: airelmin1219@qq.com
}

Xiangyue Chen

School of Translation Studies, Jinan University

Zhuhai, 519070, China

E-mail: 1916897995@qq.com 


\title{
Jingge Zhang
}

School of Foreign Languages, Jinan University

Guangzhou, 510632, China

E-mail: jarvis_is_jingge@foxmail.com

\section{Xichuan Chen}

School of Economics and Management, Zhengzhou Normal University

$$
\text { Zhengzhou, 450044, China }
$$

Zhihui He

Zhuhai Hengqin Building \& Construction Quality Inspection Centre Co.,Ltd

Zhuhai, 519031, China

\author{
Ting Qu \\ Institute of Physical Internet, Jinan University \\ Zhuhai, 519070, China \\ Congdong $\mathrm{Li}$ \\ Institute of Physical Internet, Jinan University \\ Zhuhai, 519070, China \\ Guoquan Huang \\ Institute of Physical Internet, Jinan University \\ Zhuhai, 519070, China
}

Received: September 21, 2018 Accepted: October 15, 2018 Published: October 25, 2018 doi:10.5296/gjes.v4i2.14086

URL: https://doi.org/10.5296/gjes.v4i2.14086 


\title{
Macrothink
}

\begin{abstract}
This paper focuses on the quantitative analysis of the construction and optimization of university innovation system in the integration of Chinese military and civilian. With the integration of military and civilian, colleges and innovation as the key words, data of the literatures is collected from the CNKI from 2005 to 2018, extract and pre-process the retrieval data, and then construct university innovation system in civil-military inosculation. The network uses keyword analysis, network density, centrality measurement, cluster analysis and core-edge structure analysis in the common word network analysis method to analyze keywords. This paper summarizes the characteristics of the research status of the university's innovation system in the integration of military and civilian, and proposes its future research direction, and provides reference for the further deepening and expansion of the university's innovation system under the background of military and civilian integration.
\end{abstract}

Keywords: Co-word network analysis, Keywords, Civil-military inosculation, Colleges and universities, Innovation system, Collaborative innovation 


\section{Preface}

Since the US Congressional Technical Evaluation Bureau officially proposed the construction mode of the "military and civilian integration" of the defense industry in the 1990s, the countries of the world have gradually followed the model of military-civilian cooperation and formulated various basic national policies(Ruxiang, 2009). The Chinese government has also raised the concept of "military and civilian integration" from the perspective of military resources sharing, military system development, and the establishment of a national science and technology innovation system, and has raised this to the national strategic level (Liang, 2014). As one of the main bodies of social innovation, colleges and universities are an important part of the national defense science and technology innovation system. They have the scientific and technological innovation advantages of disciplines, talents and basic research, but they also have problems in participating in the integration of military and civilian, that is, information development is inefficient, school-enterprise research. The degree of integration is low, the basic research investment is insufficient, the scientific research results are transferred, protected, and encouraged, and the current evaluation system defects in colleges and universities (Yan et al., 2018). How to build a scientific and technological innovation mechanism in colleges and universities in the context of military-civilian integration, overcome the problems encountered by universities in the implementation of national strategy of military-civilian integration, and become a research hotspot in domestic academic circles, and drive a large number of theoretical research and experimental practice.

From the perspective of direction and problems, these studies mainly focus on introducing the innovation mechanism of colleges and universities in the integration of military and civilians in other countries, the overall thinking of the coordinated innovation of schools and enterprises in the integration of military and civilian, and the promotion of the strategy of constructing such collaborative innovation mechanisms;

From the perspective of research methods, the above research mainly uses qualitative analysis, which is usually analyzed in the macroscopic sense by using the corresponding problem-corresponding strategy model. In the research on the construction and optimization of the university's innovation system in China's military-civilian integration, the existing problems and methodologies and the evolution of the research hotspot, lack of comprehensive, coherent, accurate quantitative analysis.

As one of the important application tools of bibliometrics, the common word network analysis method provides a new theoretical perspective for the study of the law of knowledge growth in various fields, allowing researchers to observe the scientific knowledge network at the level of low-level and micro-level knowledge units. Formation and evolution process (Xiaoguang, 2009).

This paper applies the common word network method to analyze the current situation and characteristics of the research and optimization of the university's innovation system in the integration of military and civilian integration in China, as well as the possible focus and development direction of future research. 


\section{1) Macrothink}

\section{Research Methods}

The common word network analysis method is a bibliometric analysis tool that combines the co-word analysis method and the social network. It is a social network constructed by the co-occurrence relationship of keywords. Its nodes are keywords, and their connection relationship is that the keyword nodes co-occur in the same article. The nature of the keyword represents the conceptual characteristics of a topic. The keyword co-occurrence network is essentially a network based on concepts and knowledge. Different concepts transfer, share and derive knowledge through the network. Therefore, the network of common words can reflect the flow and utilization of knowledge. In the process of production and development of a subject, there will be a large number of keywords or keywords that can represent the meaning of the subject. These keywords often appear together, that is, the phenomenon of co-words. These keywords have both semantic explicit connections and invisible relationships resulting from interactions.

The specific process of using the common word network analysis method to visualize keyword linkage is shown in Figure 1.

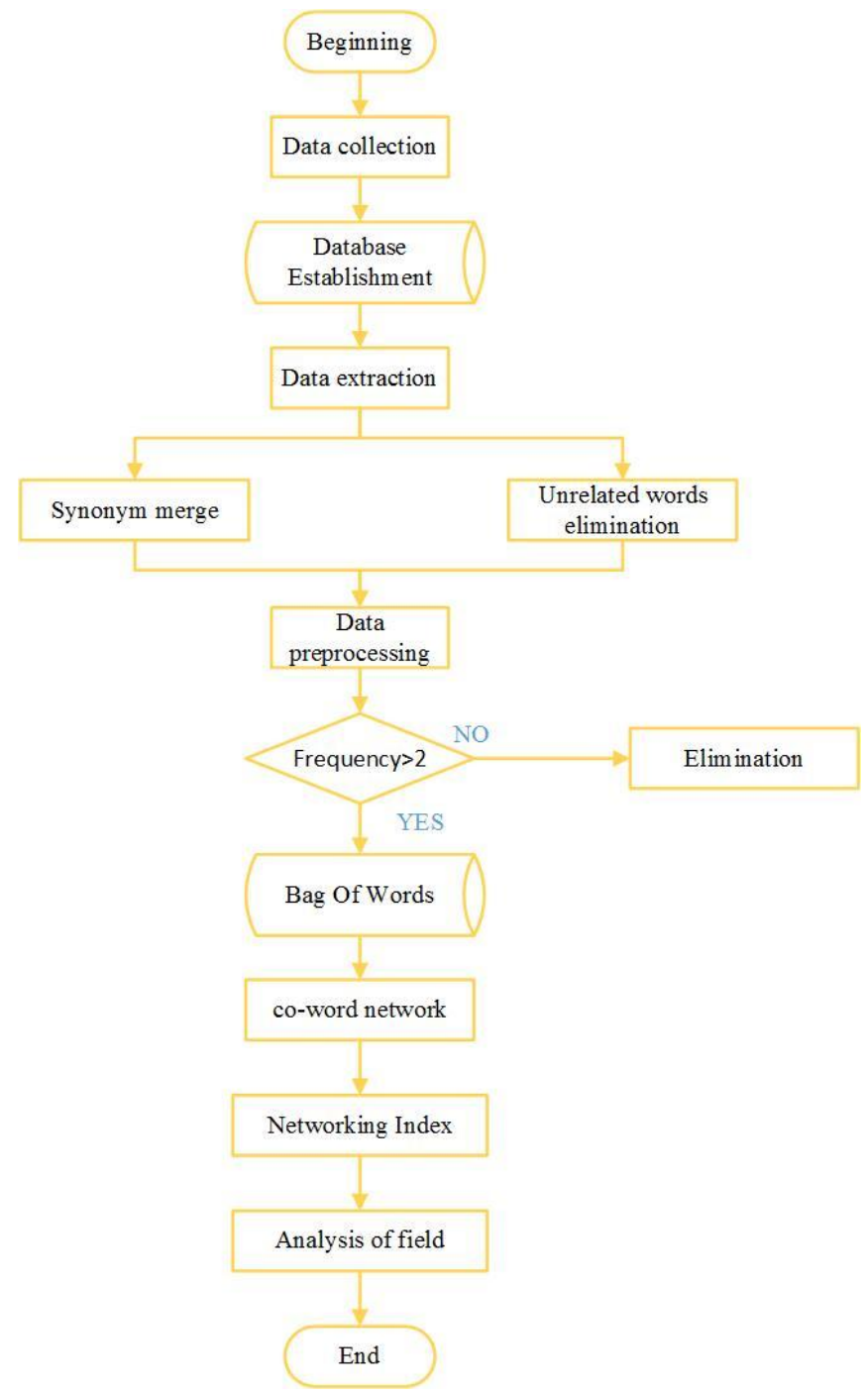

Figure 1. Co-word network analysis process 


\section{Macrothink}

Global Journal of Educational Studies

ISSN 2377-3936

2018, Vol. 4, No. 2

Collect all the research topics or directions, and extract and preprocess the literature data according to certain conditions;

Based on the co-occurrence rules for all keywords in the literature, each keyword is used as a network node to construct a keyword network;

Based on the nature of the network and the corresponding algorithm, select high-frequency keywords, and the relationship between these high-frequency keywords and other keywords to further confirm the research hotspots of the research topic or direction;

This study will use the common word network analysis method to conduct a bibliometric analysis of the research literature of the university's innovation system in military-civilian integration. The goal is to systematically analyze the research theme or research direction maturity and knowledge in the university's innovation system in military-civilian integration. The structure and scale of research will lay the foundation for deepening or expanding relevant research in the future.

\section{Data Acquisition and Preprocessing}

\subsection{Data source}

This study uses the dynamically updated Chinese academic journal network publishing library as a statistical source to truly reflect the current research situation. According to the path of China Journal Network (CNKI) - China Academic Journals Network Publishing General Library - Core Journals, the search is based on "military and civilian integration", "colleges", "innovation" as search terms, search terms are keywords, and source categories are core. Journals, the time range is 2008-2018. Divided into two categories of scientific research literature and experience introduction articles, de-emphasizing and merging the retrieved documents, and finally selecting 28 documents that meet the research requirements.

\subsection{Data Extraction}

The original vocabulary data extracted by the data source generally has problems such as irregular keyword naming, which needs to be processed, that is, merge synonyms, and delete vocabulary without relevance and domain specificity. After the original vocabulary data is deduplicated and deleted, there are 64 keywords, and the average number of documents is about 3 .

\subsection{Data Preprocessing}

Data analysis was performed using the network analysis software Gephi 0.92. The keyword data is saved in CSV format and sorted according to the frequency of occurrence of keywords; secondly, keywords with frequency less than 2 times are excluded, and only keywords with frequency higher than 2 are reserved as research objects to ensure the credibility of the research hotspots.

\section{Keywords Analysis Based on Social Network}

\subsection{Sociogram}

By applying Gephi's Fruchterman Reinggold layout algorithm, the keyword network of 


\section{Macrothink}

Global Journal of Educational Studies

ISSN 2377-3936 2018, Vol. 4, No. 2

university innovation system in civil-military integration can be drawn, that is, sociogram of university innovation system in civil-military integration. As shown in figure 2, the characteristics and correlation of keywords in the literature are reflected intuitively.

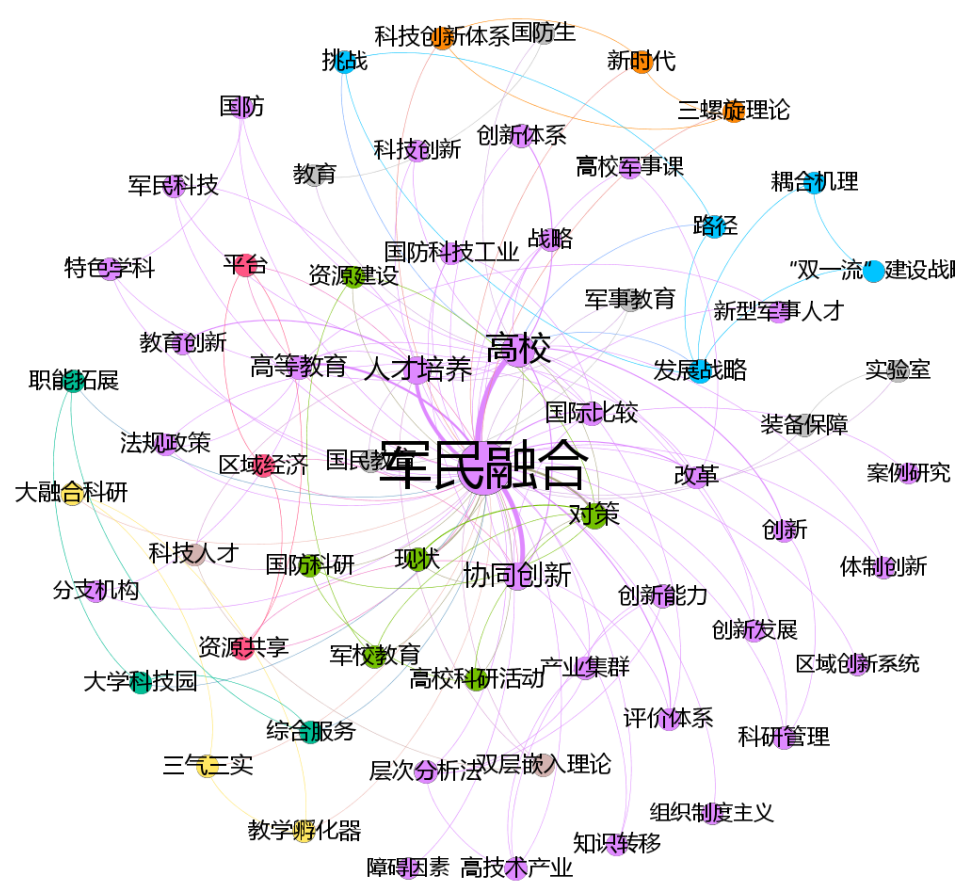

Figure 2. Sociogram of university innovation system in civil-military integration

In Figure 2, the node of network represents high-frequency keywords, and the radius of the node is directly proportional to its point centrality degree, the larger the node, the larger its point centrality degree.

The five keywords of "Civil-military Integration", "University", "Talents Cultivation", "Collaborative Innovation" and "Countermeasures" have large radius of the node, which indicates that these keywords are at the core position of the sociogram, while other keywords are the edge points of the co-word network. In the analysis of co-word network, the key words in the core position can be used as the current research priority and future research field.

\subsection{Network Density}

The network density can reflect the degree of connection between network nodes in the sociogram, and the value range is $[0,1]$. The higher the value is, the closer it is to 1 , and the higher the network density is. The network density of the sociogram of university innovation system in civil-military integration by using Gephi software to calculate is 0.068 .

Also, according to the equation:

$$
C_{n}^{2}=\frac{P_{n}^{2}}{2 !}=\frac{n !}{2 !(\mathrm{n}-2) !}
$$




\section{Macrothink}

Global Journal of Educational Studies

ISSN 2377-3936

2018, Vol. 4, No. 2

the number of edges that can be formed theoretically by pairwise correlations of all network nodes in the sociogram should be, in other words, there should be 2016 relationships between high-frequency keywords. However, the network only has 140 edges in the experiment, which means that there are only 14 relationships exists actually between high-frequency keywords. This indicates the low density of sociogram of university innovation system in civil-military integration. The depth and breadth of research in this field still need to be further improved.

\subsection{Centrality}

Centrality is used to evaluate the importance of network nodes, and the analysis of co-network mainly reflects the status of keywords in the whole network. The more central the keywords are, the more likely they are to become the research priority in the corresponding field. In this study, the eigenvalues and eigenvectors were used as to measure the centrality. When measuring the importance of the node, it is measured in terms of its own degree and the importance of each of its neighbors in the centrality of eigenvectors. Provided $\mathrm{X}$ to be the measured value of the importance of the vi node, the equation is:

$$
E C(i)=x_{i}=c \sum_{j=1}^{n} a_{i j} x_{j}
$$

$C$ is a proportionality constant, assuming that these column vectors $x=\left[x_{1}, x_{2}, x_{3}, \ldots, x_{n}\right]^{T}$ tend to be stable after multiple iterations, and the matrix form is obtained:

$$
x=c A x
$$

It represents that $\mathrm{x}$ is used as the corresponding eigenvector of matrix $\mathrm{A}$, whose eigenvalue is $c-1$. When calculating the vector $x$, initial value $x(0)$ should be set first and then iterative computations are adopted:

$$
x(t)=c A x(t-1), t=1,2, \ldots
$$

Iterative computation should not be stopped until $x^{\prime}(t)=x^{\prime}(t-1)$. During each process of iterative computation, divided $\mathrm{x}$ by the principal eigenvalue $\lambda$ of adjacent matrix $\mathrm{A}$, the equation can arrives at a convergent nonzero solution $x=\lambda^{-1} A x$, then arrives at a further solution $c=\lambda^{-1}$.

The centrality analysis of keyword network of university innovation system in civil-military integration are shown in table 1. 
Table 1. Centrality analysis of keyword network of university innovation system in civil-military integration

\begin{tabular}{|c|c|c|c|}
\hline Keyword & $\begin{array}{l}\text { Eigenvector } \\
\text { centrality }\end{array}$ & Keyword & $\begin{array}{l}\text { Eigenvector } \\
\text { centrality }\end{array}$ \\
\hline Civil-military integration & 1 & $\begin{array}{l}\text { Scientific researches in higher } \\
\text { educational institutes }\end{array}$ & 0.151325 \\
\hline University & 0.47167 & $\begin{array}{l}\text { National defense scientific } \\
\text { research }\end{array}$ & 0.151325 \\
\hline Collaborative Innovation & 0.359344 & Education of military academies & 0.151325 \\
\hline Personnel training & 0.330146 & Resources development & 0.151325 \\
\hline Countermeasure & 0.280718 & Policy & 0.148612 \\
\hline Present situation & 0.222357 & Knowledge transfer & 0.143185 \\
\hline Higher education & 0.204835 & Educational innovation & 0.140418 \\
\hline International comparison & 0.198248 & Fusion research & 0.135307 \\
\hline Evaluation system & 0.193054 & Science and technology parks & 0.135307 \\
\hline Strategy & 0.193054 & Teaching incubator & 0.135307 \\
\hline Civil-military technology & 0.190287 & An innovition system & 0.135307 \\
\hline Platform & 0.181486 & Triple elix theory & 0.135307 \\
\hline Regional economy & 0.181486 & Three stricts and Three steadies & 0.135307 \\
\hline Resource sharing & 0.181486 & New era & 0.135307 \\
\hline Innovation & 0.174119 & Function expansion & 0.135307 \\
\hline Innovation system & 0.174119 & Integrated service & 0.135307 \\
\hline National defense & 0.174119 & New-type military talent & 0.127663 \\
\hline $\begin{array}{l}\text { Research and development } \\
\text { management }\end{array}$ & 0.174119 & Affiliate & 0.127663 \\
\hline Characteristic discipline & 0.174119 & Military course in universities & 0.122271 \\
\hline $\begin{array}{l}\text { Science, technology and } \\
\text { industry for national defense }\end{array}$ & 0.164133 & Lab & 0.118815 \\
\hline National education & 0.157122 & Equipment support & 0.118815 \\
\hline Military education & 0.157122 & Case analysis & 0.105874 \\
\hline Sciense talent & 0.157122 & Regional Innovation System & 0.105874 \\
\hline
\end{tabular}




\begin{tabular}{cccc} 
Double layer embedding theory & 0.157122 & Barrier & 0.105874 \\
Analytic Bierarchy process & 0.156731 & Organizational institutionalism & 0.105874 \\
Industrial cluster & 0.156731 & Development strategy & 0.072384 \\
Innovation ability & 0.156731 & Path & 0.067621 \\
High-tech industry & 0.156731 & Challenge & 0.067621 \\
Innovation and development & 0.155743 & National defense & 0.056817 \\
Technical innovation & 0.155743 & Education & 0.056817 \\
System innovation & 0.155743 & Double first-class construction & 0.012316 \\
Revormation & & strategy & \\
\hline
\end{tabular}

\subsection{Cluster Analysis}

By means of Gephi's ForceAtlas2 layout algorithm, the clustering of the series nodes of the co-word network of the university innovation system in civil-military integration is realized. Small groups that keywords constitute respectively in the research literature is intuitively reflected in figure 3.

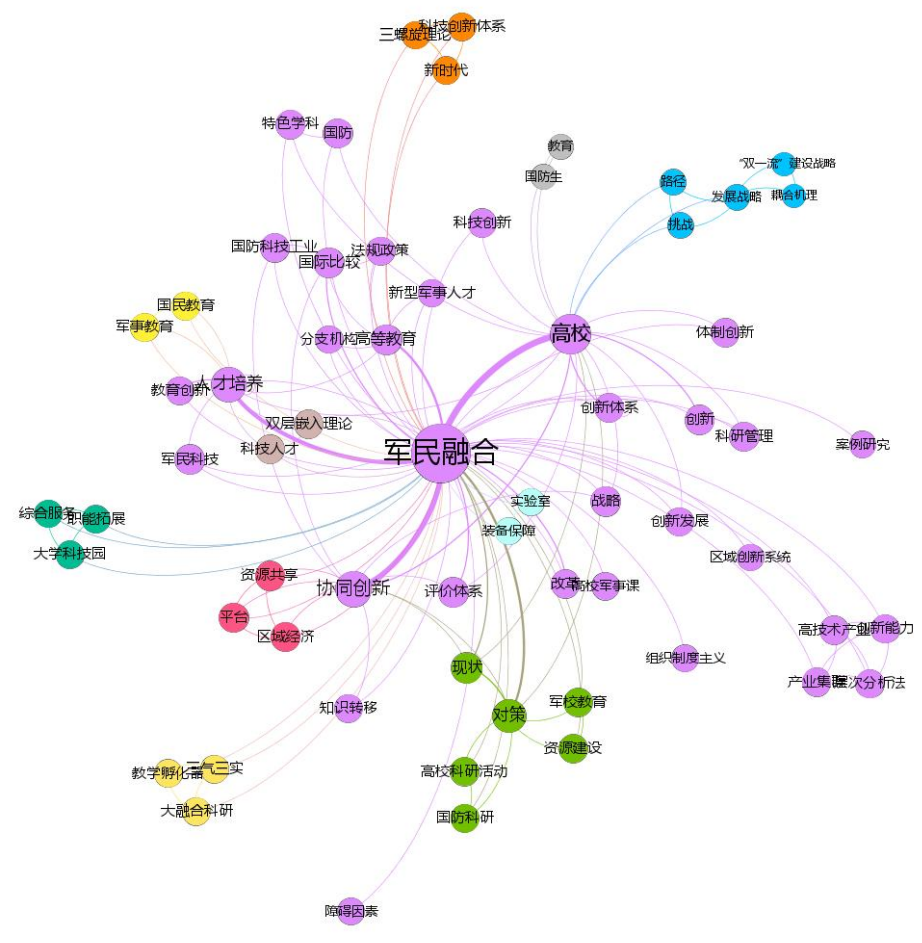

Figure 3. Clustering result 
There are a large number of small groups in the figure, divided by different colors or by different distances, with limited space. 10 groups are listed here, as shown in table 2.

Table 2. Main small groups

\begin{tabular}{cc}
\hline Number & Component of the Group \\
\hline 1 & Science and Technology Industry of National Defense, International Comparison, \\
Regulations and Policies
\end{tabular}

It can be seen from the chart analysis that the research point of talent training is the closest to the central node of the civil-military integration, indicating that it is the most basic research. New methodology is used for innovation system modeling, such as the Triple Helix Theory and Double Embedding Method, which are far away from the civil-military integration node, belonging to emerging research points, and the focus of the research direction can often be obtained from these research points.

\subsection{Analysis of "Core-Edge” Structure}

This st adopts the "core-edge" structure analysis method based on the centrality of eigenvectors to classify the location of keywords in the co-word network, mainly including core, semi-edge or edge. According to the location of the keywords, the keywords were classified into core group and edge group. In the specific measurement, the following threshold values were used to analyze the "core-edge" structure of keywords, and the results were shown in table 3. 
Table 3. Analysis of "core - edge" structure of keywords

\begin{tabular}{|c|c|c|}
\hline Category & $\begin{array}{l}\text { Threshold Value of } \\
\text { Eigenvector Centrality }\end{array}$ & Keyword \\
\hline $\begin{array}{l}\text { Core } \\
\text { Group }\end{array}$ & $(0.2,1]$ & $\begin{array}{c}\text { Civil-military Integration, University, Collaborative } \\
\text { Innovation, Talent Cultivation, Countermeasures, Current } \\
\text { Situation, Higher Education }\end{array}$ \\
\hline $\begin{array}{l}\text { Semi-edge } \\
\text { Group }\end{array}$ & $(0.1,0.2]$ & $\begin{array}{l}\text { International Comparison, Evaluation System, Strategy, } \\
\text { Civil-military Technology, Platform, Regional Economy, } \\
\text { Resource Sharing, Innovation, Innovation System, } \\
\text { National Defense, Scientific Research Management, } \\
\text { Characteristics Discipline, Science and Technology } \\
\text { Industry of National Defense, National Education, Military } \\
\text { Education, Technology Talents, Double Embedding } \\
\text { Theory, Analytic Hierarchy Process, Industrial Cluster, } \\
\text { Innovation Ability, High and New Technology Industry, } \\
\text { Innovation Development, Technological Innovation, } \\
\text { Institutional Innovation, Reform, Scientific Research } \\
\text { Activities in University, National Defense Scientific } \\
\text { Research, Education of Military Academics, Resource } \\
\text { Construction, Regulations and Policies, Knowledge } \\
\text { Transfer, Education Innovation, Great Convergence } \\
\text { Research, University Science Park, Teaching Incubator, } \\
\text { Science \& Technology Innovation System, Triple Helix } \\
\text { Theory, “Three Strength \& Three Implement”, New Era, } \\
\text { Function Expansion, Comprehensive Service, New } \\
\text { Military Personnel, Affiliated Agency, Military Course in } \\
\text { University, Laboratory, Equipment Support, Case Study, } \\
\text { Regional Innovation System, Intervening Obstacles, } \\
\text { Organizational Institutionalism }\end{array}$ \\
\hline $\begin{array}{l}\text { Edge } \\
\text { Group }\end{array}$ & $(0,0.1]$ & $\begin{array}{c}\text { Key Strategy, Route, Challenge, National Defense Student, } \\
\text { Education, Double First-class Construction Strategy, } \\
\text { Coupling Mechanism }\end{array}$ \\
\hline
\end{tabular}

\section{Conclusion}

Some characteristics of this research field can be obtained by analyzing the literature on the current university innovation system in civil-military integration.

1) From the perspective of network centrality, cluster analysis and "core-edge" structure analysis, talent cultivation system, collaborative innovation and higher education is still the current core and key direction of university innovation system research in the civil-military integration. The research points of semi-edge group and edge group, such as international comparison and the construction of rating system, are the external ones with research prospects, because most of them are still in the initial stage. 
2) From the perspective of keywords related to research methodology, keywords such as "Triple Helix Theory", "Double Embedding Theory", "Case Analysis" and "Analytic Hierarchy Process" indicate that current research methodology mainly focuses on structural theory and application analysis and lacks quantitative empirical analysis such as statistical test.

On the whole, the research on university innovation system in civil-military integration is of high homogeneity, with strong overlap between research points, lack of creativity, and weak connection between research points, indicating the lack of breadth and depth of this research field.

According to the above mentioned characteristics, relevant suggestions can be made:

In order to improve the breadth and depth of the research field, joint research can be conducted among research hot-spots, such as empirical analysis of collaborative innovation and regional economy, etc.;

In terms of research methodology, quantitative empirical research should be added on the basis of the original structural theory to explore the generation mechanism and mutual relations of various research elements in the research field of university innovation system in civil-military integration.

\section{Acknowledgements}

The research is financed by the Fundamental Research Funds for the Central Universities, China, No. 21618412, No. 21618804 and Major Scientific Research Projects of Henan Colleges and Universities in 2019, No. 19A630037. Thanks for Prof. Guo, (Jinan University).

\section{References}

Liang, A. (2014). Problems and countermeasures for advancing civil-military integration. National Defense, (3), 25-26.

Ruxiang, R. (2009). Theory and practice of civil-military integration with Chinese characteristics. China aerospace press.

Xiaoguang, W. (2009). The formation and evolution of scientific knowledge network (1): Proposal of co-word network method. Journal of Intelligence, 28(4), 599-605.

Yan, L., Yang, Z., Yeshuang, Y., \& Xinhua, G. (2018). Position and development countermeasures of the university in the civil-military integration strategy [J/OL]. Management Science Research, 1-4. https://doi.org/10.19445/j.cnki.15-1103/g3.2018.03.004

\section{Copyright Disclaimer}

Copyright for this article is retained by the author(s), with first publication rights granted to the journal.

This is an open-access article distributed under the terms and conditions of the Creative Commons Attribution license (http://creativecommons.org/licenses/by/3.0/). 